\title{
Implementasi Algoritma Apriori Terhadap Data Penjualan Oli Mobil Berbasis Sistem Pencarian Aturan Asosiasi
}

\author{
Jorza Rulianto ${ }^{1}$, Wida Prima Mustika ${ }^{2}$ \\ STMIK Nusa Mandiri Jakarta \\ Jl. Damai No. 8, Warung Jati Barat (Margasatwa) Jakarta \\ jorsarulianto@gmail.com,wida.wpm@nusamandiri.ac.id
}

\begin{abstract}
Data mining techniques are used to design effective sales or marketing strategies by utilizing sales transaction data that is already available in the company. The problem in the company is that there are many data transactions that occur unknown, causing an accumulation of data unknown sales most in each month \& year, unknown brands of car oil are often sold or demanded by customers. So this association search uses a priori algorithm as a place to store data using pattern recognition techniques such as static and mathematical techniques from a set of relationships (associations) between items obtained, it is expected that can help developers in designing marketing strategies for goods in the company. Software testing results that have been made have found the most sold oil brand products if you buy Shell Hx7, it will buy Toyota Motor Oil with 50\% support and 66.7\% confidence. If you buy Toyota Motor Oil, you will buy Shell Hx 7 with $50 \%$ support and $85.7 \%$ confidence.
\end{abstract}

Keywords: Data Mining, Apriori Algorithms, Oil brand products, Association Rules System

\begin{abstract}
Abstrak
Teknik data mining yang digunakan untuk merancang strategi penjualan atau pemasaran yang efektif dengan memanfaatkan data transaksi penjualan yang telah tersedia di perusahaan.Permasalahan di perusahaan terdapat banyak data transaksi yang terjadi tidak ketahui sehingga menimbulkan penumpukan data tidak diketahui penjualan terbanyak pada tiap bulan \& tahunnya, tidak diketahui merk oli mobil yang sering terjual atau diminati pelanggan. Sehingga Pencarian asosiasi ini menggunakan algoritma apriori sebagai tempat penyimpanan data menggunakan teknik pengenalan pola seperti teknik static dan matematika Dari suatu himpunan hubungan (asosiasi) antar item yang didapat, diharapkan yang dapat membantu pengembang dalam merancang strategi pemasaran barang di perusahaannya. Hasil pengujian perhitungan meggunakan Software tanagra dan yang telah dibuat ditemukan produk merk oli yang paling banyak terjual jika membeli Shell Hx7, maka akan membeli Toyota Motor Oil dengan support 50\% dan confidance 66,7\%, Jika membeli Toyota Motor Oil,maka akan membeli Shell Hx 7 dengan support 50\% dan confidance $85,7 \%$.
\end{abstract}

Kata kunci: Data Mining, Algoritma Apriori, Produk merk oli, Sistem Aturan Asosiasi

\section{PENDAHULUAN}

Oli atau Pelumas adalah zat kimia berupa cairan, yang diberikan di antara dua benda bergerak untuk mengurangi gaya gesek. Zat ini merupakan fraksi hasil distilasi minyak bumi yang memiliki suhu 105-135 derajat celcius, Pelumas berfungsi sebagai lapisan pelindung yang memisahkan dua permukaan yang berhubungan, Umumnya pelumas terdiri dari 90\% minyak dasar dan $10 \%$ zat tambahan, Salah satu penggunaan pelumas paling utama adalah oli mesin yang dipakai pada mesin [1]. Penelitian ini mengambil data 
penjualan oli pada PT. Nilam Sejahtera Brs Kevin Motor Jakarta. PT. Nilam Sejahtera Brs Kevin Motor adalah perusahaan yang bergerak dibidang jasa service sparepart ataupun barang lainnya, seperti oli dari penjualan di PT. Nilam Sejahtera Brs Kevin Motor dari tahun 2018 terdapat banyak data transaksi yang terjadi tidak diketahui sehingga menimbulkan penumpukan data dan tidak diketahui merk oli mobil yang sering terjual atau diminati pelanggan.

\section{METODOLOGI PENELITIAN}

Algoritma Apriori termasuk jenis aturan asosiasi pada data mining. Selain a priori, yang termasuk pada golongan ini adalah metode Generalized Rule Induction dan Algoritma Hash Based. Aturan yang menyatakan asosiasi antara beberapa atribut sering disebut affinity analysis atau market based analysis". Analisis asosiasi atau association rule mining adalah teknik data mining untuk menemukan aturan asosiatif antara suatu kombinasi item.

Analisis asosiasi dikenal juga sebagai salah satu teknik data mining yang menjadi dasar dari berbagai teknik data mining lainnya. Secara khusus salah satu tahap analisis asosiasi yang menarik perhatian banyak peneliti untuk menghasilkan algoritma yang efisien adalah analisis pola frekuensi tinggi (frequent pattern mining). Penting tidaknya suatu aturan asosiatif dapat diketahui dengan dua parameter, yaitu support dan confidence. Support (nilai penunjang) adalah presentase kombinasi item tersebut dalam database, sedangkan confidence (nilai kepastian) adalah kuatnya hubungan antar-item dalam aturan asosiasi. Metedologi dasar analisis asosiasi terbagi menjadi dua tahap, yaitu [2] :

a) Analisis Pola Frekuensi Tinggi

Tahap ini mencari kombinasi item yang memenuhi syarat minimum dari nilai support dalam database. Nilai support sebuah item diperoleh dengan rumus berikut:

\begin{tabular}{|c|}
\hline \\
Support $(A)=\quad$ Total transaksi
\end{tabular}

Sementara itu, nilai support dari 2 item diperoleh dari rumus 2 berikut.

\begin{tabular}{|c|}
\hline Support $(A, B)=P(A \cap B)$ \\
Support $(A, B)=\quad \sum$ Transaksi mengandung $A$ dan $B$ \\
\cline { 2 - 2 }
\end{tabular}

b) Pembentukan Aturan Asosiasi

Setelah semua pola frekuensi tinggi ditemukan, barulah dicari aturan asosiasi yang memenuhi syarat minimum untuk confidence dengan menghitung confidence aturan asosiatif $\mathrm{A} \leftrightarrow \mathrm{B}$. Nilai confidence dari aturan $\mathrm{A} \rightarrow \mathrm{B}$ diperoleh dari rumus berikut :

$$
\text { Confidence }=P(B \mid \mathrm{A})=\frac{\sum \text { Transaksi mengandung } A \text { dan } B}{\sum \text { Transaksi mengandung } A}
$$

Implementasi Algoritma Apriori Terhadap Data Penjualan Oli Mobil (Jorza Rulianto)|317 
Tanagra adalah software data mining bebas untuk tujuan akademik dan penelitian ini mengusulkan beberapa metode data mining dari analisis eksplorasi data,pembelarajan statistik, pembelajaran mesin dan daerah database.Tanagra adalah"proyek open source"karena setiap penelitian dapat mengakses ke kode sumber, dan menambahkan algoritma sendiri, sejauh dia setuju dan sesuai dengan lisensi distribusi perangkat lunak[3].

Penjualan adalah konsep lugas yang di antaranya berupa usaha membujuk pelanggan untuk membeli sebuah produk. Penjualan merupakan syarat mutlak keberlangsungan suatu usaha, karena dengan penjualan maka akan didapatkan keuntungan. Semakin tinggi penjualan maka keuntungan yang akan didapatpun akan semakin maksimal. Untuk mencapai tujuan ini maka sangat diperlukan usaha-usaha agar konsumen mempunyai daya tarik dan sifat loyal dalam berbelanja disuatu unit usaha [4].

\subsection{Desain Penelitian}

Berikut adalah kerangka penelitian Implementasi Algoritma Apriori Terhadap Data Penjualan Oli Mobil Berbasis Sistem Pencarian Aturan Asosiasi:

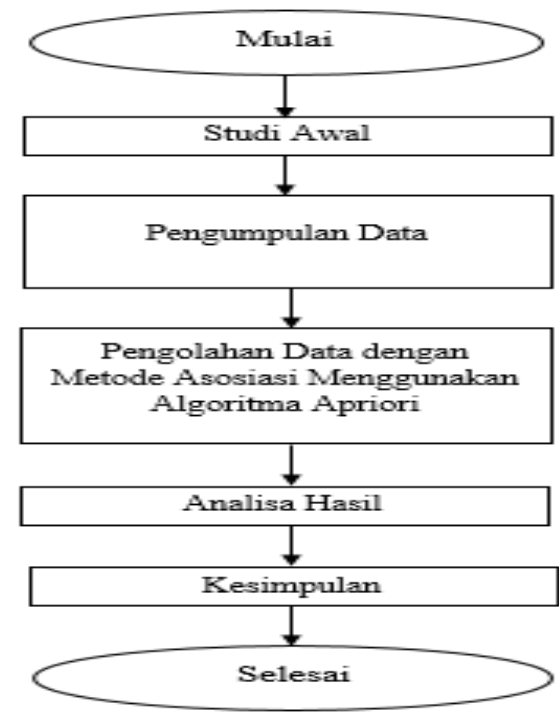

Gambar 1. Kerangka Penelitian

\subsection{Teknik Pengumpulan Data}

Pengumpulan data akan dilakukan melalui langkah sebagai berikut :

a) Data Primer

Data rekapitulasi dan informasi penelitian ini diperoleh dari perusahaan terkait yaitu, data penjualan produk oli pada bulan januari 2018 desember 2018 pada PT. Nilam Sejahtera Brs Kevin Motor.

b) Observasi

Untuk melengkapi penelitian ini penulis melakukan observasi untuk mengumpulkan data yang diperlukan. Penulis melakukan pencatatan dan pengumpulan data-data atau dokumen yang berkaitan dengan data 
penjualan oli mobil pada PT. Nilam Sejahtera Brs Kevin Motor di daerah cibinong.

c) Wawancara

Penulis memperoleh data - data serta meneliti kebenaran informasi dari data-data tersebut dengan melakukan, tanya jawab secara langsung dengan pemilik PT. Nilam Sejahtera Brs Kevin Motor.

\section{HASIL DAN PEMBAHASAN}

\subsection{Analisa Pembahasan Dengan Algoritma Apriori}

Tahap dalam menganalisa data dengan algoritma apriori pada data penjualan merk oli mobil dimulai dengan menyeleksi dan membersihkan datadata yang akan dianalisis, kemudian dicari semua jenis merk oli mobil yang ada didalam transaksi penjualan. Selanjutnya dicari jumlah setiap merk oli mobil yang ada pada transaksi penjualan.

Tabel 1. Daftar Produk Merk Oli

\begin{tabular}{|c|l|}
\hline No & \multicolumn{1}{|c|}{ Produk Merk Oli } \\
\hline 1 & Shell Hx 7 \\
\hline 2 & Shell Hx 5 \\
\hline 3 & Castrol Magnatec \\
\hline 4 & ATF DEX III \\
\hline 5 & Prima Xp \\
\hline
\end{tabular}

\section{a) Pola Transaksi Penjualan Merk Oli Mobil}

Berdasarkan data transaksi penjualan merk oli mobil pada PT. Nilam Sejahtera Brs Kevin Motor selama 1 tahun didapatkan pola transaksi dengan menganalisis 3 produk merk oli mobil yang paling banyak terjadi setiap bulannya.

Tabel 2. Pola Transaksi Penjualan Produk Merk Oli

\begin{tabular}{|l|l|}
\hline Bulan & Item Set \\
\hline 1 & Shell Hx 7, ATF DEX lll, Toyota Motor Oil \\
\hline 2 & Shell Hx 7, Shell Hx 5, Toyota Motor Oil \\
\hline 3 & Castrol Magnatec, ATF DEX lll, Toyota Motor Oil \\
\hline 4 & Shell Hx 7, Shell Hx 5, ATF DEX III \\
\hline 5 & Shell Hx 7, ATF DEX III, Toyota Motor Oil \\
\hline 6 & Shell Hx 7, Castrol Magnatec, Toyota Motor Oil \\
\hline 7 & Shell Hx 7, Shell Hx 5, Toyota Motor Oil \\
\hline 8 & Shell Hx 7, Shell Hx 5, Castrol Magnatec \\
\hline 9 & Shell Hx 7, Castrol Magnatec,Toyota Motor Oil \\
\hline 10 & Shell Hx 7, Castrol Magnatec,ATF DEX III \\
\hline 11 & Shell Hx 5, Castrol Magnatec, ATF DEX III \\
\hline
\end{tabular}

\section{b) Pembuatan Format Tabular}

Format Tabular data transaksi bulanan, bila dibentuk akan tampak seperti Tabel IV. 15 berikut ini 
Tabel 3. Format Tabular Data Transaksi

\begin{tabular}{|c|c|c|c|c|c|}
\hline Bulan & $\begin{array}{c}\text { shell } \\
\text { hx 7 }\end{array}$ & $\begin{array}{c}\text { Shell } \\
\text { hx 5 }\end{array}$ & $\begin{array}{c}\text { Castrol } \\
\text { Magnatec }\end{array}$ & $\begin{array}{c}\text { ATF } \\
\text { DEX III }\end{array}$ & $\begin{array}{c}\text { Toyota } \\
\text { Motor Oil }\end{array}$ \\
\hline $\mathbf{1}$ & 1 & 0 & 0 & 1 & 1 \\
\hline $\mathbf{2}$ & 1 & 1 & 0 & 0 & 1 \\
\hline $\mathbf{3}$ & 0 & 0 & 1 & 1 & 1 \\
\hline $\mathbf{4}$ & 1 & 1 & 0 & 1 & 0 \\
\hline $\mathbf{5}$ & 1 & 0 & 0 & 1 & 1 \\
\hline $\mathbf{6}$ & 1 & 0 & 1 & 0 & 1 \\
\hline $\mathbf{7}$ & 1 & 1 & 0 & 0 & 1 \\
\hline $\mathbf{8}$ & 1 & 1 & 1 & 0 & 0 \\
\hline $\mathbf{9}$ & 1 & 0 & 1 & 0 & 1 \\
\hline $\mathbf{1 0}$ & 1 & 0 & 1 & 1 & 0 \\
\hline $\mathbf{1 1}$ & 0 & 1 & 1 & 1 & 0 \\
\hline $\mathbf{1 2}$ & 0 & 1 & 1 & 1 & 0 \\
\hline TOTAL & 9 & 6 & 7 & 7 & 7 \\
\hline
\end{tabular}

\subsection{Analisa Pola Frekuensi Tinggi}

\section{a) Pembentukan 1 Itemset}

Proses pembentukan $\mathrm{C}_{1}$ atau disebut dengan 1 itemset dengan jumlah minimum support $=30 \%$. Dengan rumus sebagai berikut :

$$
\operatorname{Support}(A)=\frac{\Sigma \text { Transaksi yang mengandung A }}{\Sigma \text { Transaksi }} * 100 \%
$$

Berikut merupakan perhitungan pembentukan 1 itemset :

$$
\begin{aligned}
& \text { S(Shell Hx 7) } \\
= & \frac{\sum \text { Transaksi Shell Hx } 7}{\sum 12}=\frac{9}{12} * 100 \%=75 \%
\end{aligned}
$$

Tabel 4. Support dari 1 itemset

\begin{tabular}{|l|c|c|}
\hline \multicolumn{1}{|c|}{ Itemset } & Jumlah & Support \\
\hline Shell Hx 7 & 9 & $75 \%$ \\
\hline Shell Hx 5 & 6 & $50 \%$ \\
\hline Castrol Magnatec & 7 & $58 \%$ \\
\hline ATF DEX III & 7 & $58 \%$ \\
\hline Toyota Motor Oil & 7 & $58 \%$ \\
\hline
\end{tabular}

\section{b) Kombinasi 2 itemset}

Proses pembentukan $\mathrm{C}_{2}$ atau disebut dengan 2 itemset dengan jumlah minimum support $=30 \%$. Dapat diselesaikan dengan rumus sebagai berikut :

$$
\text { Support }(A, B)=P(A \cap B)
$$

Support $(A, B)=\frac{\sum \text { Transaksi yang mengandung A,B }}{\sum \text { Transaksi }} * 100 \%$

Berikut merupakan perhitungan pembentukan $\mathrm{C} 2$ atau 2 itemset : 
S(Shell Hx 7, Shell Hx 5)

$=\frac{\sum \text { Transaksi Shell Hx } 7 \text { dan Shell Hx } 5}{\sum 12}=\frac{4}{12} * 100 \%=33 \%$

Tabel 5. Calon 2 itemset

\begin{tabular}{|l|c|c|}
\hline \multicolumn{1}{|c|}{ Itemset } & Jumlah & Support \\
\hline Shell Hx 7, Shell Hx 5 & 4 & $33 \%$ \\
\hline Shell Hx 7, CastrolMagnatec & 4 & $33 \%$ \\
\hline Shell Hx 7, ATF DEX III & 4 & $33 \%$ \\
\hline Shell Hx 7, Toyota Motor Oil & 6 & $50 \%$ \\
\hline Shell Hx 5, Castrol Magnatec & 3 & $25 \%$ \\
\hline Shell Hx 5, ATF DEX III & 3 & $25 \%$ \\
\hline Shell Hx 5, Toyota Motor Oil & 2 & $16 \%$ \\
\hline Castrol Magnatec, ATF DEX III & 4 & $33 \%$ \\
\hline Castrol Magnatec, Toyota Motor Oil & 3 & $25 \%$ \\
\hline ATF DEX III, Toyota Motor Oil & 3 & $25 \%$ \\
\hline
\end{tabular}

\section{c) Kombinasi 3 itemset}

Proses pembentukan $\mathrm{C}_{3}$ atau disebut dengan 3 itemset dengan jumlah minimum 30\% Dapat diselesaikan dengan rumus sebagai berikut :

$$
\text { Support }(A, B, \text { dan } C)=\frac{\sum \text { Transaksi yang mengandung } A, B \text { dan } C}{\sum \text { Transaksi }} * 100 \%
$$

Berikut merupakan perhitungan pembentukan C3 atau 3 itemset :

Support (Shell Hx 7, Shell Hx 5 dan Castrol Magnatec)

$=\frac{\Sigma \text { Transaksi Shell } H x \text { 7, Shell Hx } 5 \text { dan Castrol Magnatec }}{\Sigma \text { Transaksi }}=\frac{1}{12} * 100 \%=8,33 \%$

Tabel 6. Kombinasi 3 itemset

\begin{tabular}{|c|c|c|}
\hline Itemset & Jumlah & Support \\
\hline Shell Hx 7, Shell Hx 5, Castrol Magnatec & 1 & $8,33 \%$ \\
\hline Shell Hx 7, Shell Hx 5, ATF DEX III & 1 & $8,33 \%$ \\
\hline Shell Hx 7, Shell Hx 5, Toyota Motor Oil & 2 & $16 \%$ \\
\hline Shell Hx 7, Castrol Magnatec, ATF DEX III & 1 & $8,33 \%$ \\
\hline Shell Hx 7, Castrol Magnatec, Toyota Motor Oil & 2 & $16 \%$ \\
\hline Shell Hx 7, ATF DEX III, Toyota Motor Oil & 2 & $16 \%$ \\
\hline Shell Hx 5, Castrol Magnatec, ATF DEX III & 2 & $16 \%$ \\
\hline Shell Hx 5, Castrol Magnatec, Toyota Motor Oil & 0 & $0 \%$ \\
\hline Shell Hx 5, ATF DEX III, Toyota Motor Oil & 0 & $0 \%$ \\
\hline Castrol Magnatec, ATF DEX III, Toyota Motor Oil & 1 & $8,33 \%$ \\
\hline
\end{tabular}

\section{d) Pembentukan Aturan Asosiasi}

Setelah semua pola frekuensi tinggi ditemukan, baru dicari aturan asosiasi yang memenuhi syarat minimum Confidence dengan menghitung Confidence aturan asosiatif $\mathrm{A} \rightarrow \mathrm{B}$

Minimal Confidence $=60 \%$

Nilai Confidence dari aturan $\mathrm{A} \rightarrow \mathrm{B}$ diperoleh dengan rumus sebagai berikut : 


$$
\text { Confidence }=P(A / B)=\frac{\Sigma \text { Transaksi yang mengandung A dan B }}{\Sigma \text { Transaksi } A} * 100 \%
$$

Berikut merupakan perhitungan Confidence :

a. $\quad$ Confidence $=P($ Shell $H x 7 /$ Shell $H x$ 5)

$=\frac{\sum \text { Transaksi Shell Hx } 7 \text { Dan Shell Hx } 5}{\sum \text { Shell Hx } 7}=\frac{4}{9} * 100 \%=44 \%$

b. $\quad$ Confidence $=P($ Shell $\mathrm{Hx} 5 \backslash$ Shell $\mathrm{Hx} 7)$

$=\frac{\sum \text { Transaksi Shell Hx } 5 \text { dan Shell Hx } 7}{\sum \text { Shell Hx } 5}=\frac{4}{6} * 100 \%=66 \%$

Tabel 7. Calon Aturan Asosiasi

\begin{tabular}{|l|c|c|}
\hline \multicolumn{1}{|c|}{ Aturan } & \multicolumn{2}{|c|}{ Confidence } \\
\hline $\begin{array}{l}\text { Jika membeli Shell Hx 7, maka akan } \\
\text { membeli Shell Hx 5 }\end{array}$ & $\mathbf{4} / \mathbf{9}$ & $\mathbf{4 4 \%}$ \\
\hline $\begin{array}{l}\text { Jika membeli Shell Hx 5, maka akan } \\
\text { membeli Shell Hx 7 }\end{array}$ & $\mathbf{4 / 6}$ & $\mathbf{6 6 \%}$ \\
\hline $\begin{array}{l}\text { Jika membeli Shell Hx 7, maka akan } \\
\text { membeli Castrol Magnatec }\end{array}$ & $\mathbf{4} / \mathbf{9}$ & $\mathbf{4 4 \%}$ \\
\hline $\begin{array}{l}\text { Jika membeli Castrol Magnatec, } \\
\text { maka akan membeli Shell Hx 7 }\end{array}$ & $\mathbf{4 / 7}$ & $\mathbf{5 7 \%}$ \\
\hline $\begin{array}{l}\text { Jika membeli Shell Hx 7, maka akan } \\
\text { membeli ATF DEX III }\end{array}$ & $\mathbf{4 / 9}$ & $\mathbf{4 4 \%}$ \\
\hline $\begin{array}{l}\text { Jika membeli ATF DEX III, maka } \\
\text { akan membeli Shell Hx 7 }\end{array}$ & $\mathbf{4 / 7}$ & $\mathbf{5 7 \%}$ \\
\hline $\begin{array}{l}\text { Jika membeli Shell Hx 7, maka akan } \\
\text { membeli Toyota Motor Oil }\end{array}$ & $\mathbf{6 / 9}$ & $\mathbf{8 5 , 7 \%}$ \\
\hline $\begin{array}{l}\text { Jika membeli Toyota Motor Oil, } \\
\text { maka akan membeli Shell Hx 7 }\end{array}$ & $\mathbf{6 / 7}$ & $\mathbf{5 7 \%}$ \\
\hline $\begin{array}{l}\text { Jika membeli Castrol Magnatec, } \\
\text { maka akan membeli ATF DEX III }\end{array}$ & $\mathbf{4 / 7}$ & $\mathbf{5 7 \%}$ \\
\hline $\begin{array}{l}\text { Jika membeli ATF DEX III, maka } \\
\text { akan membeli Castrol Magnatec }\end{array}$ & $\mathbf{4 / 7}$ & \\
\hline
\end{tabular}

\section{e) Aturan Asosiasi Final}

Memenuhi minimal support 30\% dan minimal confidence $60 \%$ dapat dilihat pada tabel berikut ini :

Tabel 8. Aturan Asosiasi Final

\begin{tabular}{|c|c|c|}
\hline Aturan & Support & Confidence \\
\hline $\begin{array}{c}\text { Jika membeli Shell Hx 7, maka akan membeli Toyota } \\
\text { Motor Oil }\end{array}$ & $50 \%$ & $66,7 \%$ \\
\hline $\begin{array}{c}\text { Jika membeli Toyota Motor Oil, maka akan membeli } \\
\text { Shell Hx } 7\end{array}$ & $50 \%$ & $85,7 \%$ \\
\hline
\end{tabular}




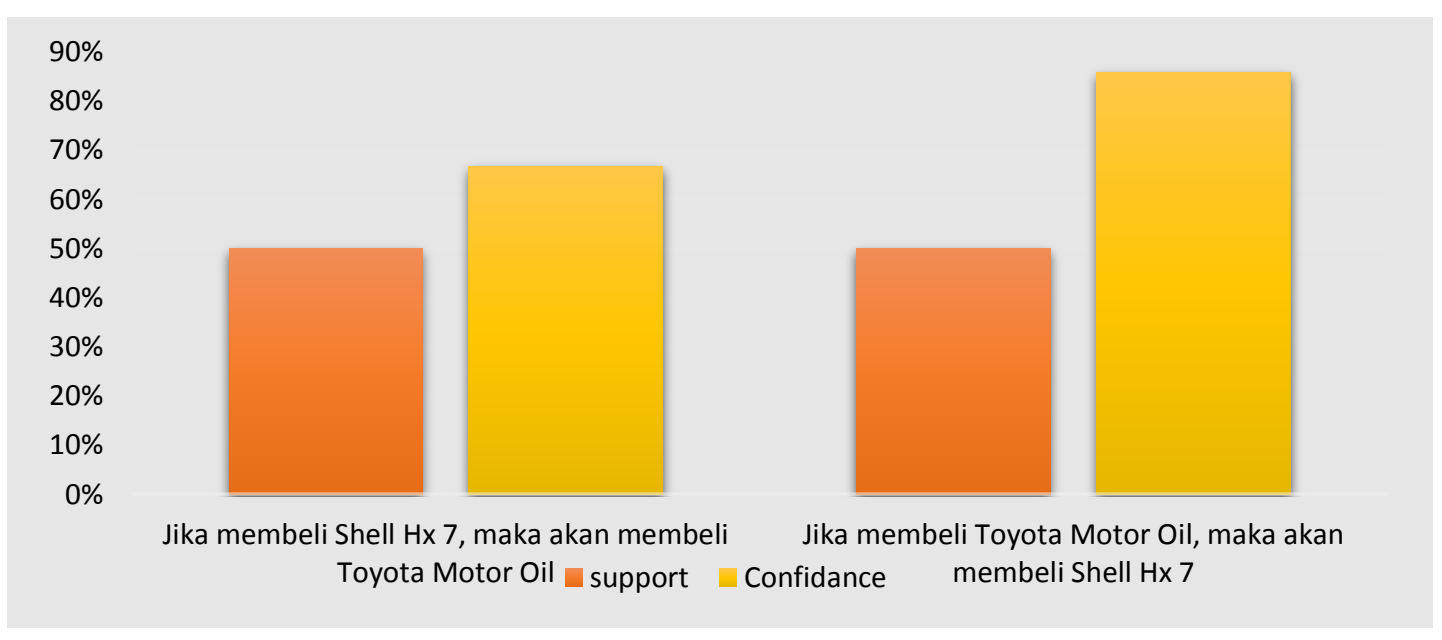

Gambar 2. Diagram Hasil Pembentukan Aturan Asosiasi Final Penjualan Terbanyak

Jadi berdasarkan grafik diatas, produk merk oli yang paling banyak terjual adalah jika membeli Shell Hx7, maka akan membeli Toyota Motor Oil dengan support $50 \%$ dan confidance 66,7\%, Jika membeli Toyota Motor Oil, maka akan membeli Shell Hx 7 dengan support 50\% dan confidance 85,7\%, dengan diketahui produk yang paling banyak terjual tersebut, sehingga perusahaan dapat meneliti apa kelebihan produk yang paling banyak terjual tersebut dengan produk lainnya dan dapat menambah persediaan produk merk oli yang paling banyak terjual di PT. Nilam Sejahtera Brs Kevin Motor

\subsection{Perhitungan Algoritma Apriori dengan Tanagra}

a) Memasukan file excel yang berisi table tabular dan memilih format excel yaitu xlss.

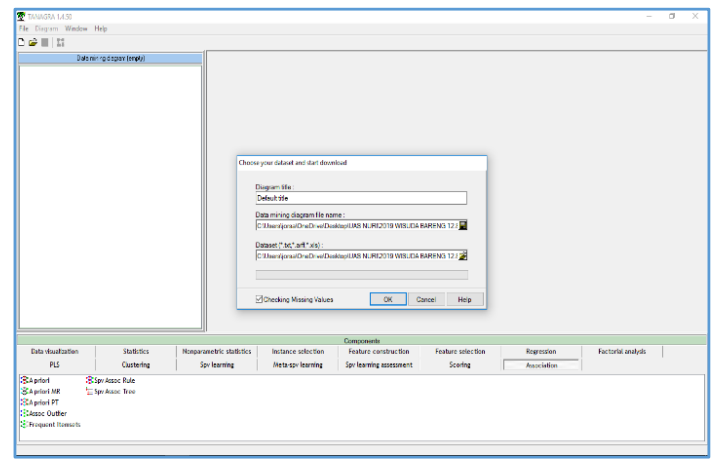

Gambar 3. Memasukkan File Excel 
b) Memindahkan Oli di dalam Attribute ke dalam input

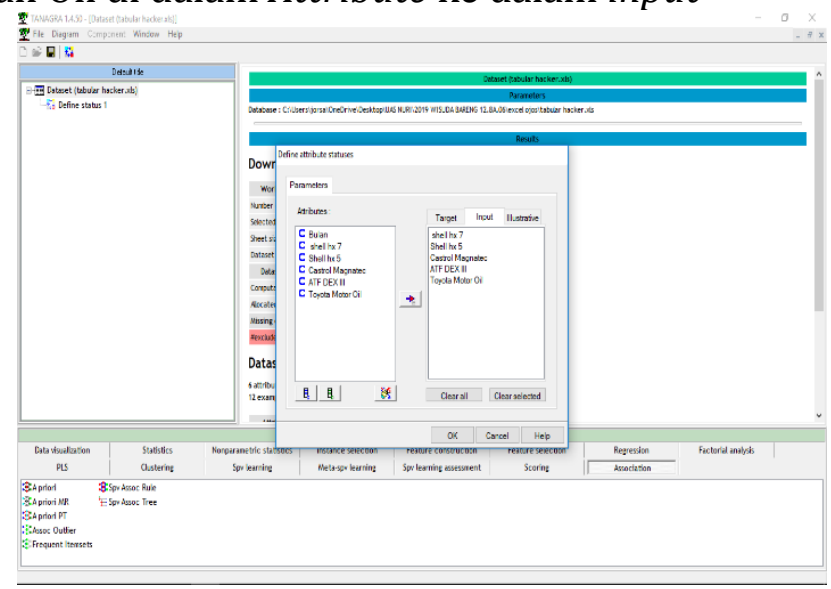

Gambar 4. Memasukkan Oli sebagai Input

c) Tampilan dari hasil 2 kombinasi itemset

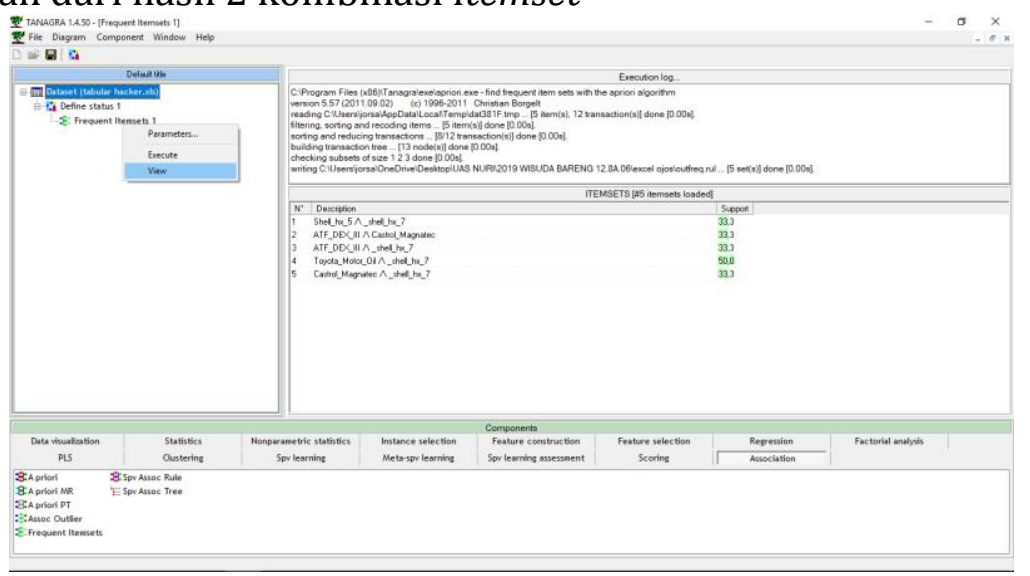

Gambar 5. Kombinasi 2 item set

d) Maka akan muncul tampilan dari hasil 2 kombinasi itemset yang memenuhi minimal support dan confidance

RULES

\begin{tabular}{|c|c|c|c|c|c|}
\hline \multicolumn{6}{|c|}{ Number of rules : 2} \\
\hline $\mathrm{N}^{2}$ & Antecedent & Consequent & Lift & Support (\%) & Confidence (\%) \\
\hline 1 & "shell hx $7=$ true" & "Toyota Motor Oil=true" & 1,14286 & 50,000 & 66,667 \\
\hline 2 & "Toyota Motor Oil=true" & " shell hx $7=$ true" & 1,14286 & 50,000 & 85,714 \\
\hline
\end{tabular}

Gambar 6. Hasil Kombinasi 2 item set

\subsection{Implementasi Sistem Pencarian Aturan Asosiasi Final}

Sistem Pencarian Aturan Asosiasi Final adalah sistem yang diterapkan untuk memudahkan menentukan rules data penjualan dengan menerapkan Algoritma Apriori dalam sebuah sistem. Sistem ini terdiri dari Objek Item, Pengaturan dan Proses Perhitungan. 
Jurnal Sains Komputer \& Informatika (J-SAKTI)

Volume 3 Nomor 2 September 2019, pp. 316-326

ISSN:2548-9771/EISSN:2549-7200

http://tunasbangsa.ac.id/ejurnal/index.php/jsakti

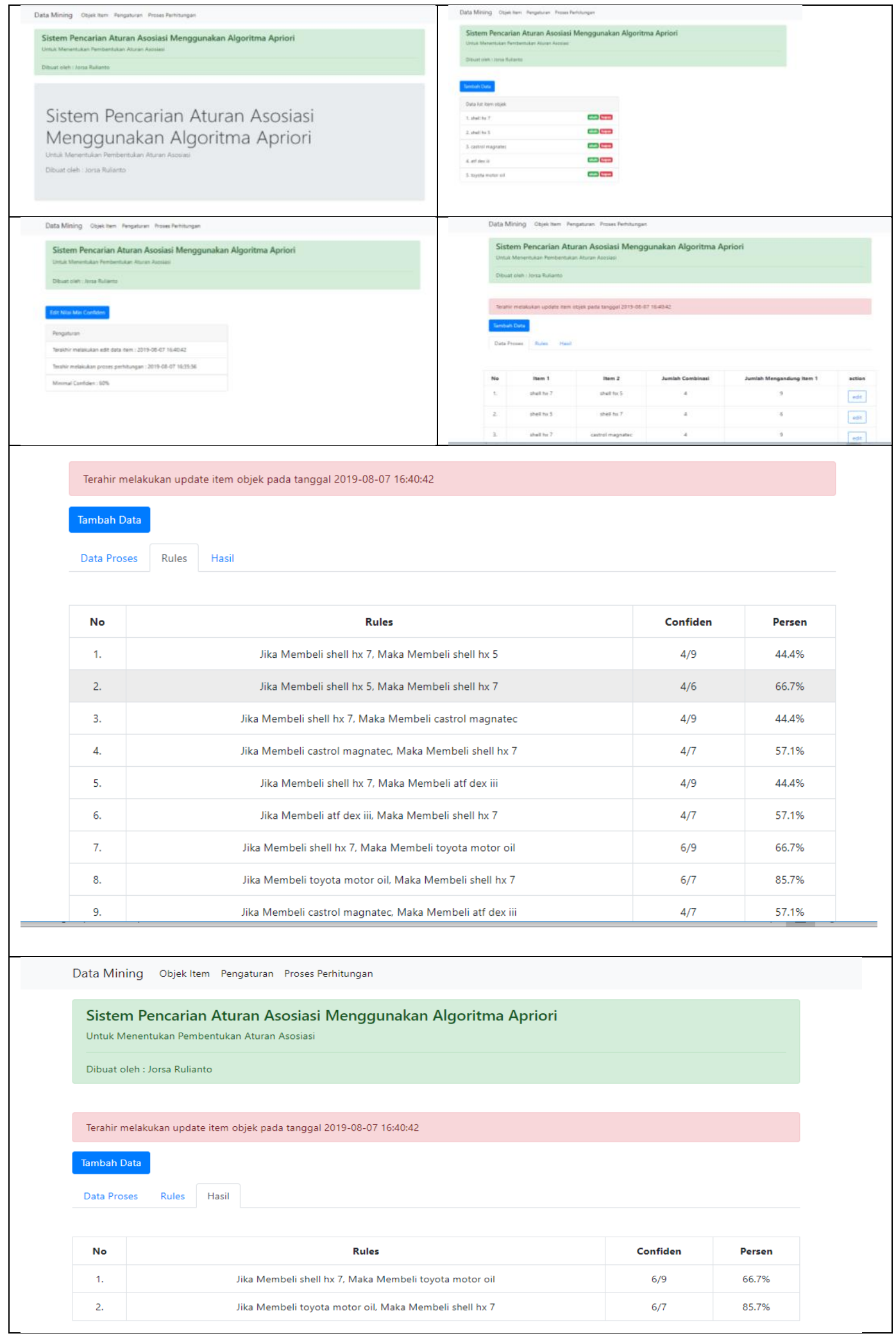

Tampilan Aturan Asosiasi Final Yaitu jika membeli Shell Hx7, maka akan membeli Toyota Motor Oil dengan confidance 66,7\%, Jika membeli Toyota Motor Oil, maka akan membeli Shell Hx 7 dengan confidance 85,7\%.

Implementasi Algoritma Apriori Terhadap Data Penjualan Oli Mobil (Jorza Rulianto)|325 


\section{SIMPULAN}

Algoritma apriori sangat berguna untuk mengetahui hubungan pola frekuensi penjualan produk merk oli yang paling sering terjual. Dengan algoritma apriori dapat ditemukan produk merk oli yang paling banyak terjual dan hasil yang memenuhi syarat minimum confidence $60 \%$ seperti Jika membeli Shell Hx 7, maka akan membeli Toyota Motor Oil 67,7\% Jika membeli Toyota Motor Oil, maka akan membeli Shell Hx 7 85,7\%.

\section{DAFTAR PUSTAKA}

[1] Mardyaningsih, M., \& Leki, A. [2014]. Jurnal teknik mesin. Jurnal Teknik Mesin

[2] Kusrini, \& Luthfi, E. T. [2009]. Algoritma Data Mining. Yogyakarta: Andi Offset.

[3] Badrul, M. [2016]. Algoritma asosiasi dengan algoritma apriori untuk analisa data penjualan. Pilar NusaMandiri, XII(2), 121-129.

[4] Komalasari, R. G. Dan E. [2016]. Analisis Faktor-Faktor Yang Mempengaruhi Teluk Kuantan. Jurnal Valuta.

[5] Sarwadi \& Cyber Creative. [2017]. JAGO Microsoft Excel 2016 (1st ed.). Surabaya: Elex Media Komputindo.

[6] Agustina, S. [2011]. Manajemen Permasaran (1st ed.). Malang. 